\title{
Oral steroid-sparing effect of high-dose inhaled corticosteroids in asthma
}

\author{
Ingrid Maijers ${ }^{1}$, Nethmi Kearns (1) ${ }^{1}$, James Harper (10), Mark Weatherall ${ }^{2}$ and \\ Richard Beasley (1) ${ }^{1,3}$
}

Affiliations: ${ }^{1}$ Medical Research Institute of New Zealand, Wellington, New Zealand. ${ }^{2}$ Dept of Medicine, University of Otago Wellington, Wellington, New Zealand. ${ }^{3}$ School of Biological Sciences, Victoria University of Wellington, Wellington, New Zealand.

Correspondence: Richard Beasley, Medical Research Institute of New Zealand, Private Bag 7902, Newtown, Wellington 6242, New Zealand. E-mail: richard.beasleydmrinz.ac.nz

@ERSpublications

In oral corticosteroid-dependent asthma, the majority of the oral corticosteroid-sparing effects of high-dose inhaled corticosteroids (ICS) are due to their systemic effects. Clinicians should be aware of this bioequivalence when prescribing high-dose ICS. http://bit.ly $/ 2 \mathrm{~m} 0 \mathrm{Fa} 8 \mathrm{~m}$

Cite this article as: Maijers I, Kearns N, Harper J, et al. Oral steroid-sparing effect of high-dose inhaled corticosteroids in asthma. Eur Respir J 2020; 55: 1901147 [https://doi.org/10.1183/13993003.01147-2019].

\section{ABSTRACT}

Background: The proportion of the efficacy of high-dose inhaled corticosteroids (ICS) in oral corticosteroid-dependent asthma that is due to systemic effects is uncertain. This study aimed to estimate the ICS dose-response relationship for oral corticosteroid-sparing effects in oral corticosteroid-dependent asthma, and to determine the proportion of oral corticosteroid-sparing effects due to their systemic effects, based on the comparative dose-response relationship of ICS versus oral corticosteroids on adrenal suppression.

Methods: Systematic review and meta-analysis of randomised controlled trials reporting oral corticosteroid-sparing effects of high-dose ICS in oral corticosteroid-dependent asthma. In addition, reports of oral corticosteroid to ICS dose-equivalence in terms of adrenal suppression were retrieved. The primary outcome was the proportion of the oral corticosteroid-sparing effect of ICS that could be attributed to systemic absorption, per $1000 \mu \mathrm{g}$ increase of ICS, expressed as a ratio. This ratio estimates the oral corticosteroid sparing effect of ICS due to systemic effects.

Results: 11 studies including 1283 participants reporting oral corticosteroid-sparing effects of ICS were identified. The prednisone dose decrease per $1000 \mu \mathrm{g}$ increase in ICS varied from $2.1 \mathrm{mg}$ to $4.9 \mathrm{mg}$, depending on the type of ICS. The ratio of the prednisone-sparing effect due to the systemic effects per $1000 \mu \mathrm{g}$ of fluticasone propionate was 1.02 (95\% CI 0.68-2.08) and for budesonide was 0.93 (95\% CI 0.63-1.89).

Conclusion: In patients with oral corticosteroid-dependent asthma, the limited available evidence suggests that the majority of the oral corticosteroid-sparing effect of high-dose ICS is likely to be due to systemic effects. 


\section{Introduction}

Inhaled corticosteroids (ICS) are the cornerstone of the pharmacological treatment for asthma [1]. ICS treatment increases lung function, improves quality of life and reduces asthma symptoms, and lowers the risk of exacerbations, asthma-related hospitalisations and death [1]. The therapeutic dose-response relationship of ICS in adults is well established, with $80-90 \%$ of the maximum achievable benefit being obtained with "low" doses, 100-200 $\mu \mathrm{g}$ per day of fluticasone propionate, or equivalent, for major clinical outcome variables including lung function, symptoms and risk of severe exacerbations [2]. The maximum therapeutic effect is achieved with "medium" doses, $\sim 500 \mu \mathrm{g}$ per day of fluticasone propionate or equivalent, in patients with moderate to severe asthma [2]. At this dose level, patients are at increasing risk of systemic adverse effects, such as adrenal suppression, cataracts, fractures and diabetes [3-6].

However, ICS are commonly prescribed at inappropriately high doses. In one report from Australia, over two-thirds of the defined daily dose of ICS was supplied in the highest dose preparations of budesonide and fluticasone propionate [7], and in another report from Scotland over half of patients prescribed an ICS/long-acting $\beta$-agonist (LABA) for the first time, were prescribed "high-dose" combination therapy [8]. Key issues with high-dose ICS therapy are the extent to which there is any additional therapeutic benefit in patients with the most severe forms of asthma such as oral corticosteroid-dependent asthma, and whether this additional efficacy is actually attributable to systemic absorption. For example, systemic effects of corticosteroids may be necessary in certain patients to inhibit cytokine-related recruitment pathways that contribute to eosinophilic airway inflammation [9].

The aim of this study was to estimate the ICS dose-response relationship for oral corticosteroid-sparing effect in oral corticosteroid-dependent asthma in adults, and to then determine the component due to systemic absorption. This was based on published data of the comparative dose-response relationship of ICS versus oral corticosteroid causing adrenal suppression. If the oral corticosteroid dose-sparing effect of high-dose ICS is similar to the estimated systemic corticosteroid effect, it may be inferred that the therapeutic effect of high-dose ICS is primarily due to systemic effects rather than local airway action. If the evidence is consistent with this hypothesis then the important clinical implications are that increasing the dose of ICS to high or very high doses requires similar considerations as starting maintenance low-dose oral corticosteroid therapy, and that an alternative to increasing the dose of ICS to high or very high doses might be to start maintenance low-dose oral corticosteroid therapy. Thus, this study does not attempt to address whether high-dose ICS or low-dose prednisone is more harmful, but rather what ICS dose results in equivalent systemic effects to oral prednisone, and what proportion of the oral corticosteroid-sparing effect of high-dose ICS is due to its systemic absorption.

\section{Methods}

This review is registered with PROSPERO (registration number: CRD42019119674).

\section{Search strategy}

PubMed, Embase and the Cochrane Library were searched for randomised controlled trials published from 1960 to present, assessing the oral corticosteroid-sparing effect of lower versus high-dose ICS in corticosteroid-dependent adolescent or adult asthma patients.

The following search terms were used to identify papers:

asthma AND (steroid or corticosteroid or corticosteroid or fluticasone or flovent or flixotide or beclomethasone or beclometasone or becloforte or becotide or QVAR or budesonide or pulmicort or flunisolide or aerobid or bronalide or triamcinolone or kenalog or beclovent or azmacort or vanceril or aerobec or ciclesonide or Alvesco or prednisone or prednisolone) AND (inhaled or aerosol) AND oral.

In all databases, the search was limited to clinical trials published in the English language. The references of included papers were searched for additional potentially relevant trials. The date of the search of the databases was December 10, 2018.

In order to estimate ICS to oral corticosteroid dose equivalence in terms of systemic effects, studies using an adrenocorticotropic hormone (ACTH) stimulation test to assess adrenal suppression were identified $[10,11]$. Studies using other measures of adrenal suppression, such as plasma cortisol or serial urinary cortisol were excluded. Search terms for this search can be found in the online study protocol.

\section{Eligibility criteria}

We included studies in adolescent or adult patients with oral corticosteroid-dependent asthma. Only randomised controlled trials comparing the change in oral corticosteroid dose following administration of 
high-dose (as defined by Global Initiative for Asthma (GINA) asthma guidelines [1]) versus a lower dose ICS were included. Studies in children, those involving nebulised corticosteroids, and studies conducted in acute asthma were excluded.

\section{Study selection}

All search results relating to oral corticosteroid-sparing effects were imported into Covidence (www. covidence.org), an online software tool for management of systematic reviews. Titles of studies retrieved using the search strategy were filtered for duplicates then screened by two independent reviewers to identify potentially eligible studies. Abstracts for these titles were then screened further to identify potential studies. The full text of these studies were retrieved and independently assessed for eligibility by two reviewers. If there was uncertainty about eligibility of studies for the review this was resolved through discussion with a third reviewer.

\section{Outcomes}

For the assessment of oral corticosteroid dose reduction in relation to increasing ICS dose, the outcome was oral corticosteroid dose at the end of the study assessment period, for each of the doses of ICS used in a particular study.

The relationship between oral corticosteroid dose and ICS dose to cause adrenal suppression was quantified as prednisone mg per $1000 \mu \mathrm{g}$ increase in ICS dose.

The primary inferential outcome was the ratio of the oral corticosteroid dose causing equivalent adrenal suppression per unit dose of ICS to the oral corticosteroid-sparing per unit dose of ICS. For example, if dose-response studies of ICS " $X$ " showed that a daily dose increase of $1000 \mu \mathrm{g}$ caused the same degree of adrenal suppression as $5 \mathrm{mg}$ oral prednisone, and studies in oral corticosteroid-dependent asthma showed that ICS "X" achieved $5 \mathrm{mg}$ greater oral prednisone-sparing effect than placebo, then the ratio would be 1.0, i.e. the proportion of the oral corticosteroid dose-sparing effect due to the systemic absorption of ICS is estimated to be $100 \%$.

A secondary outcome was the odds ratio for the proportions of research participants with total oral corticosteroid elimination ( $0 \mathrm{mg}$ prednisone) per unit dose of ICS.

\section{Data extraction}

Data extraction from eligible studies included study setting, study sample characteristics, demographic descriptors, recruitment details, details on the intervention and controls, outcomes and information for assessment of the risk of bias. The data were extracted independently by two reviewers and reviewed in combination to confirm data values.

\section{Risk of bias assessment}

Two reviewers assessed the risk of bias in each study, using the Cochrane risk of bias tool. The characteristics considered were random sequence generation, allocation concealment, blinding, completeness of outcome data, selective outcome reporting and any other source of bias.

\section{Data synthesis and statistical methods}

To estimate the regression coefficient relating oral corticosteroid dose and ICS dose, inverse variance weighted regression was used, with a random intercept term for study, based on the mean and standard deviation of oral corticosteroid dose at each dose of ICS. This gives a regression coefficient with $95 \%$ confidence interval for dose response. In the event, as the identified studies only had two doses of ICS, only a linear relationship could be fitted.

Logistic regression was used to estimate the odds ratio for oral corticosteroid elimination per $1000 \mu \mathrm{g}$ unit dose increase in ICS dose. Where only one study was available, ordinary logistic regression was used. Where more than one study was available a mixed generalised linear model, using logistic regression, was used, treating study as a random effect.

Bubble plots were used to show the estimated regression line and $95 \%$ confidence limits for the mean corticosteroid dose reduction, based on the mixed linear model regression. For budesonide and beclomethasone dipropionate (BDP), the prednisone slope estimates were based on end-point prednisone dose. For fluticasone propionate and mometasone, these plots were based on the change from baseline, as data on covariance for end-point prednisone was not extractable.

SAS version 9.4 (SAS Institute, Cary, NC, USA) was used. 


\section{Results}

Study selection

A total of 1088 studies on oral corticosteroid-sparing were screened for eligibility, of which 10 studies [12-21] were included in the analyses. During background literature review one additional study [22] was identified from a previous Cochrane review [23] and was included in the analyses, for a total of 11 studies. The Preferred Reporting Items for Systematic Reviews and Meta-Analyses (PRISMA) flow diagram of the search strategy is depicted in figure 1.

\section{Study characteristics}

The 11 studies included a total of 1283 participants. The participants in all the studies had oral corticosteroid-dependent asthma. The majority of studies used a run-in period to establish the lowest maintenance dose of prednisone while maintaining asthma control, or collected information on the participant's lowest tolerable prednisone dose from their medical records. Prespecified protocols for the reduction of prednisone dose were used in seven studies; in three studies the prednisone dose was reduced at the investigators discretion; one study did not specify how decisions on prednisone reduction were made. The duration of ICS treatment varied from 12 to 26 weeks. Five different types of ICS were used in the 11 included studies. Three studies used budesonide, three fluticasone propionate, two BDP, two mometasone and one study used ciclesonide. An overview of the study characteristics is shown in table 1.

\section{Risk of bias}

The risk of bias assessment is shown in figure 2. The majority of the studies did not provide information on sequence generation or allocation concealment. All studies had a double-blind design.

\section{Proportion of oral corticosteroid effect due to systemic effects}

For the assessment of the relationship between ICS dose and adrenal suppression two publications were identified, one a meta-analysis of studies of fluticasone propionate [10] and the other a study of budesonide [11]. As a result, this assessment was only available for fluticasone propionate and budesonide. In both the identified studies the ICS dose which resulted in the same magnitude of adrenal suppression as $10 \mathrm{mg}$ of prednisone was estimated.

The meta-analysis by MASOLI et al. [10] identified two placebo-controlled studies [24, 25] in which adrenal function was assessed following 4 weeks' treatment with different doses of fluticasone propionate and

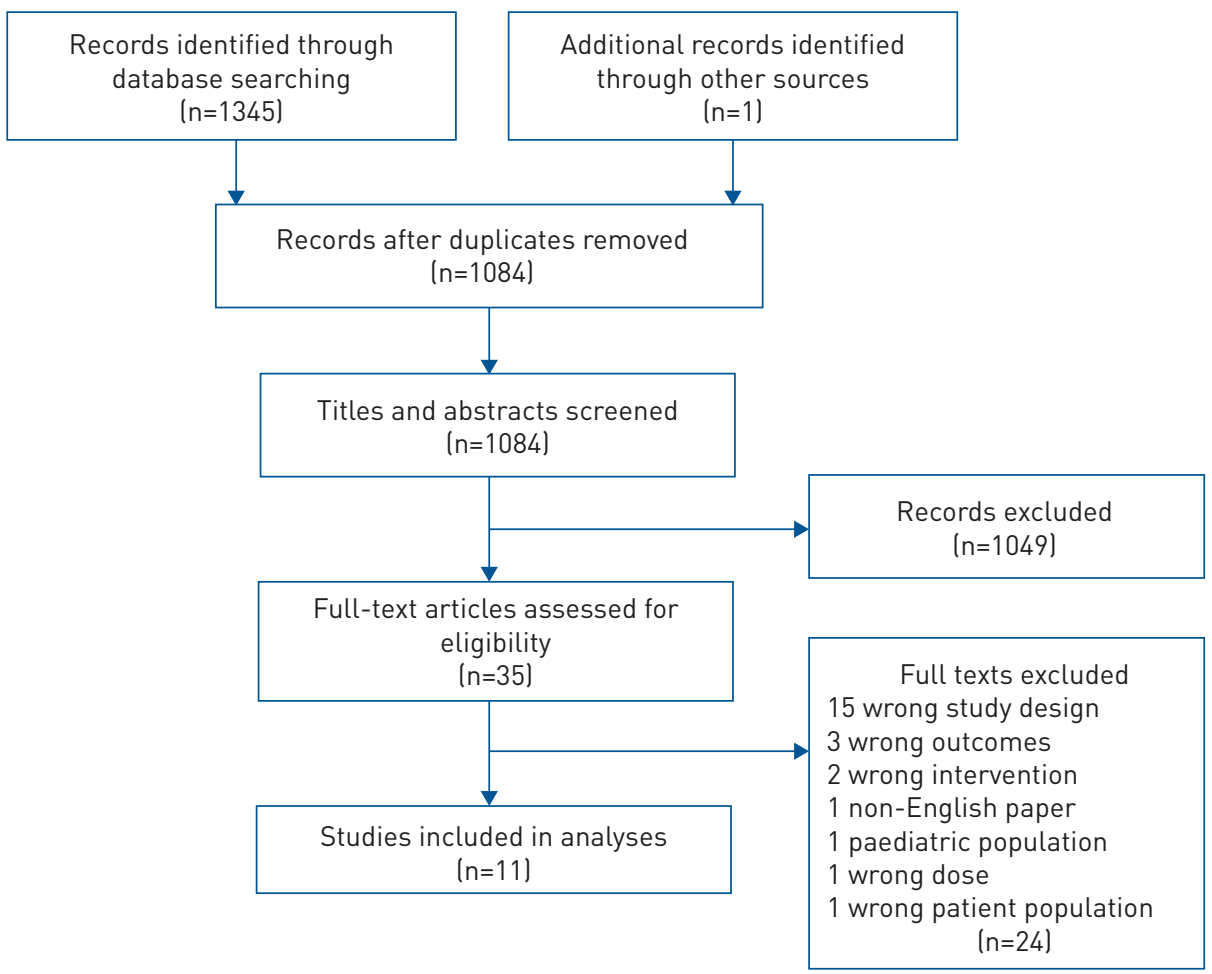

FIGURE 1 Preferred Reporting Items for Systematic Reviews and Meta-Analyses (PRISMA) flow diagram. 
TABLE 1 Characteristics of included studies

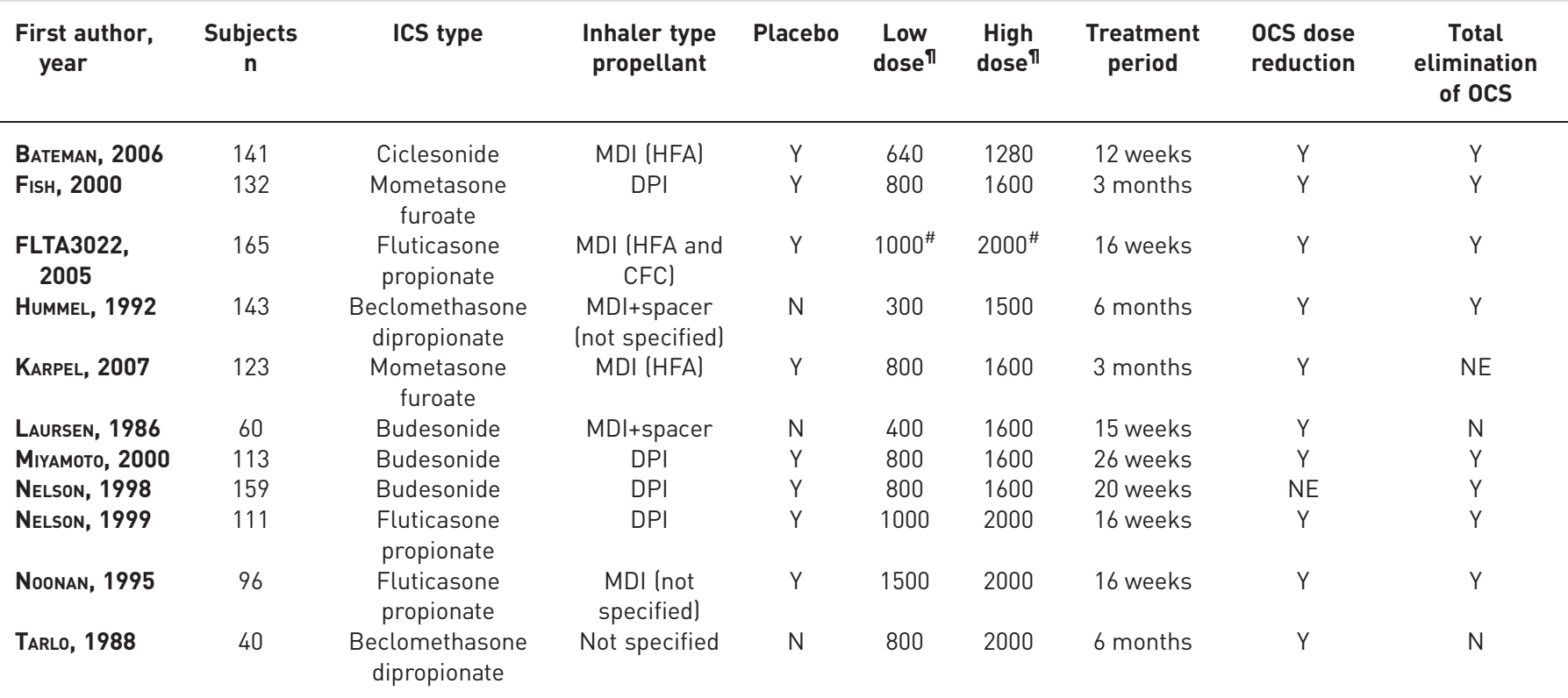

ICS: inhaled corticosteroid; Y: yes; N: no data; OCS: oral corticosteroid; MDI: metered-dose inhaler; HFA: hydrofluoroalkane; DPI: dry-powder

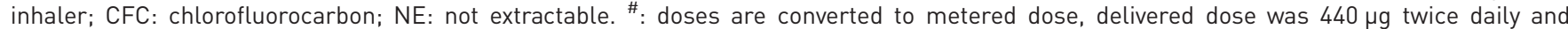
$880 \mu \mathrm{g}$ twice daily; ${ }^{\text {ๆ }}$ : $\mu \mathrm{g}$ per day.

\begin{abstract}
$10 \mathrm{mg}$ prednisone daily by measurement of mean peak plasma cortisol concentration with $6 \mathrm{~h} 0.25 \mathrm{mg}$ cosyntropin stimulation, or the 8-h area under the concentration-time course curve for plasma cortisol. By linear regression it was estimated that $10 \mathrm{mg}$ prednisone once daily was equivalent to $2000 \mu \mathrm{g}$ inhaled fluticasone propionate, suggesting that fluticasone propionate $1000 \mu \mathrm{g}$ per day was equivalent to $5 \mathrm{mg}$ per day of oral prednisone.

In a placebo-controlled study, AAronson et al. [11] assessed the effect on adrenal function of 6 weeks' treatment with different doses of budesonide and prednisone $10 \mathrm{mg}$ daily, by measurement of mean plasma cortisol concentration at the end of a $6-\mathrm{h} 0.25 \mathrm{mg}$ cosyntropin infusion. By linear regression, it was estimated that $10 \mathrm{mg}$ prednisone daily was equivalent to $5000 \mu \mathrm{g}$ per day inhaled budesonide. This
\end{abstract}

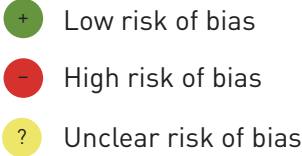

Random sequence generation (selection bias)

Allocation concealment (selection bias)

Blinding of participants and personnel (performance bias)

Blinding of outcome assessment (detection bias)

Incomplete outcome data (attrition bias)

Selective reporting (reporting bias)

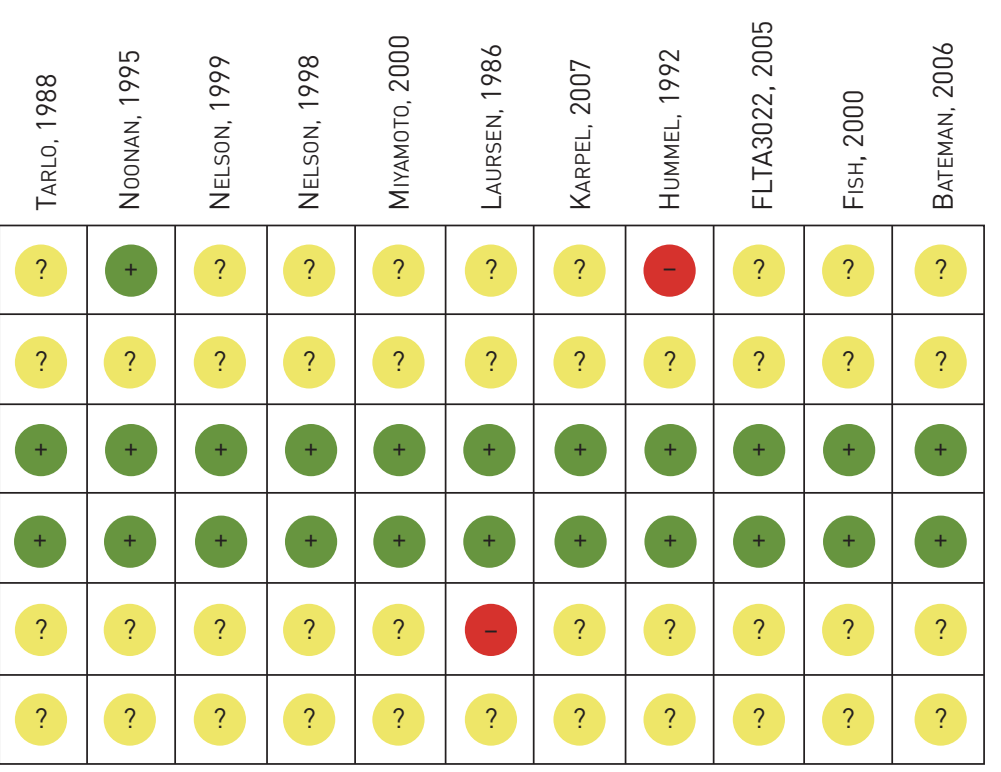

FIGURE 2 Risk of bias summary. 
suggests that budesonide $1000 \mu \mathrm{g}$ per day is equivalent to $2 \mathrm{mg}$ prednisone per day. These analyses assume a linear relationship between ICS dose and adrenal suppression, as has been demonstrated previously [10].

\section{Oral corticosteroid dose reduction}

Nine studies were included in the analysis for oral corticosteroid dose reduction in relation to different doses of ICS. There was one study of budesonide [18] that did not report sufficient data from which variance could be extracted and could therefore not be included in the analyses. Only one study for ciclesonide [12] was identified, so no meta-regression for this ICS type could be performed. The extracted summary data for prednisone dose at study end-point and change from baseline by ICS type and dose are summarised in table 2 .

Three placebo-controlled studies had extractable data for prednisone reduction in relation to fluticasone propionate dose. The difference between the highest and lowest (placebo) dose was $2000 \mu \mathrm{g}$ per day in all studies. The estimated prednisone difference $(95 \% \mathrm{CI})$ in change from baseline between the highest and lowest dose was $15.3(8.5-22.1) \mathrm{mg}$ [22], $7.8(3.9-11.7) \mathrm{mg}$ [19], and 10.9 (7.8-14.0) $\mathrm{mg}$ [20]. The meta-regression estimates were for a prednisone decrease of 4.9 (2.4-7.4) $\mathrm{mg}$ per $1000 \mu \mathrm{g}$ increase in fluticasone propionate dose. A plot of the change from baseline in prednisone dose versus fluticasone propionate dose is shown in figure $3 \mathrm{a}$.

Two studies had extractable data for prednisone reduction for budesonide; one study was placebo-controlled and the other was not placebo-controlled, with the highest dose of $1600 \mu \mathrm{g}$ per day. The estimated prednisone difference $(95 \% \mathrm{CI})$ at end-point between the highest and lowest dose of ICS was $3.9(1.5-6.2) \mathrm{mg}$ [17] and $2.0(0.7-4.7) \mathrm{mg}$ [16] for the two studies with a difference of $1600 \mu \mathrm{g}$ per

TABLE 2 Oral corticosteroid dose reduction and elimination per dose of inhaled corticosteroid (ICS)

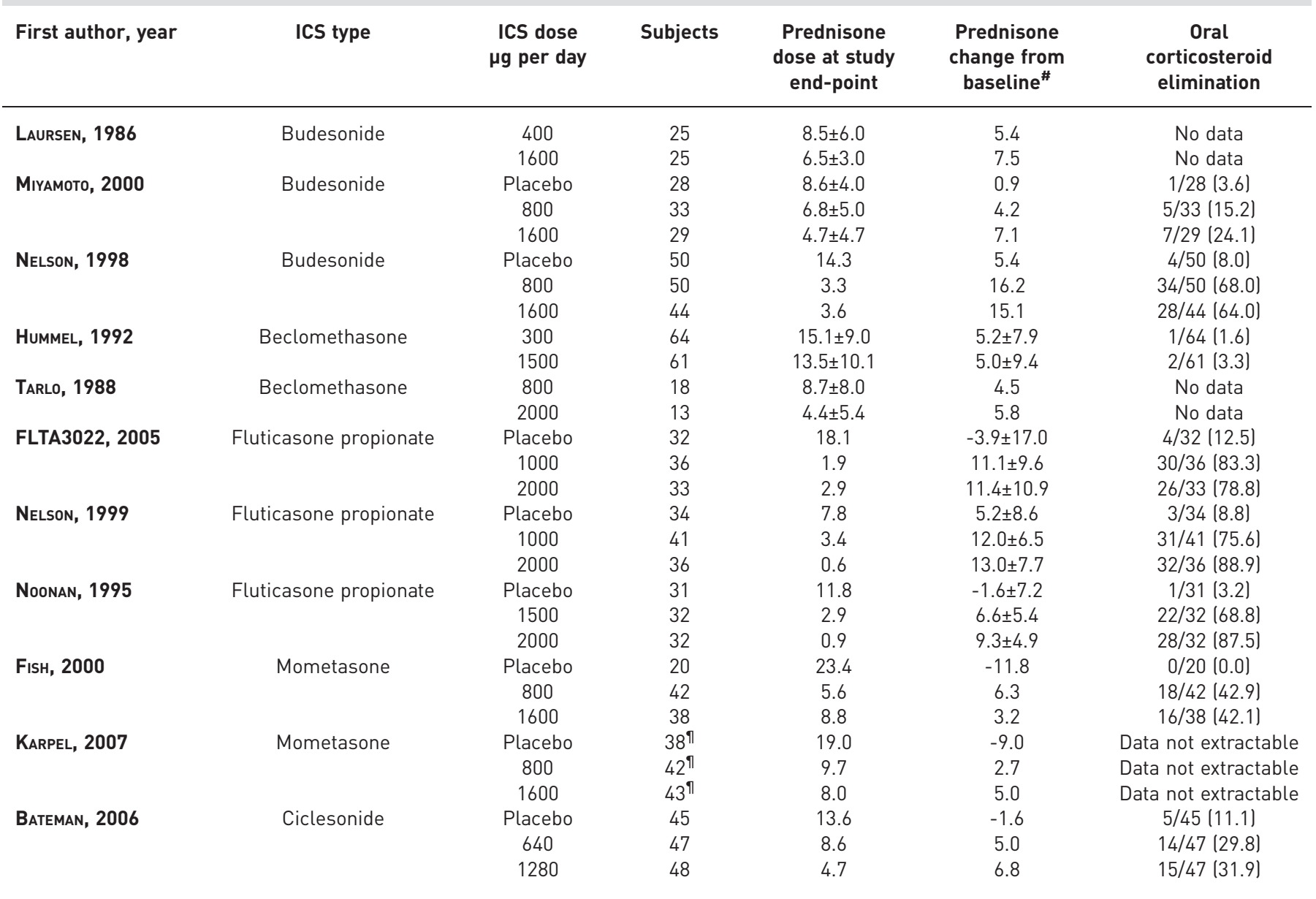

Data are presented as $\mathrm{n}$, mean \pm SD or $\mathrm{n} / \mathrm{n}(\%) .{ }^{\text {\# }}$ : prednisone dose at baseline minus prednisone dose at study end-point; ${ }^{\text {? }}$ : baseline values, as study end-point values were not extractable. 
a)

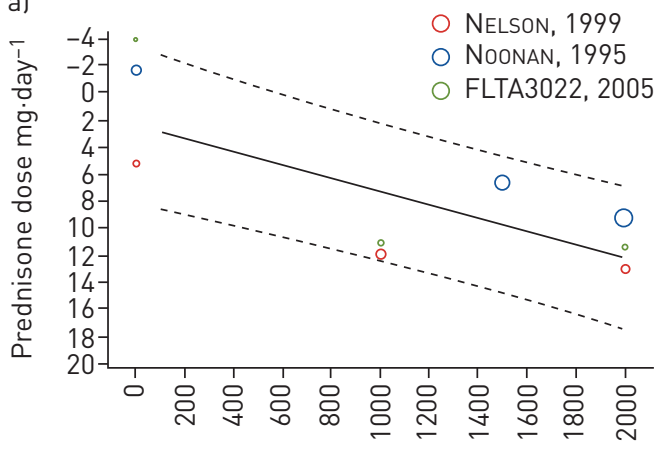

Fluticasone dose $\mu \mathrm{g} \cdot$ day $^{-1}$

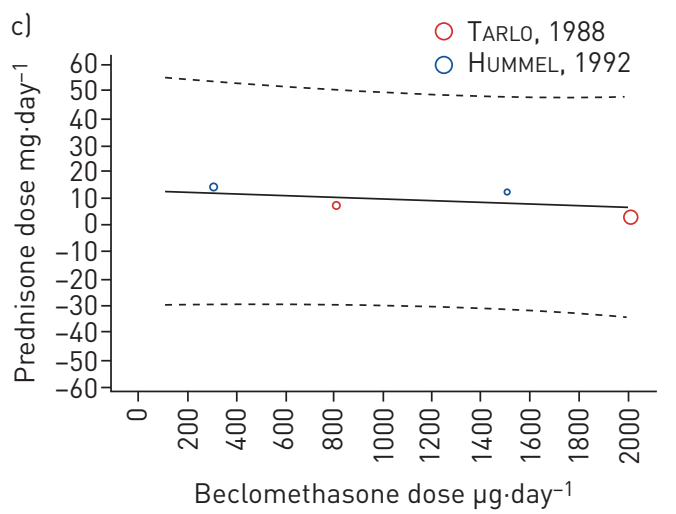

b)

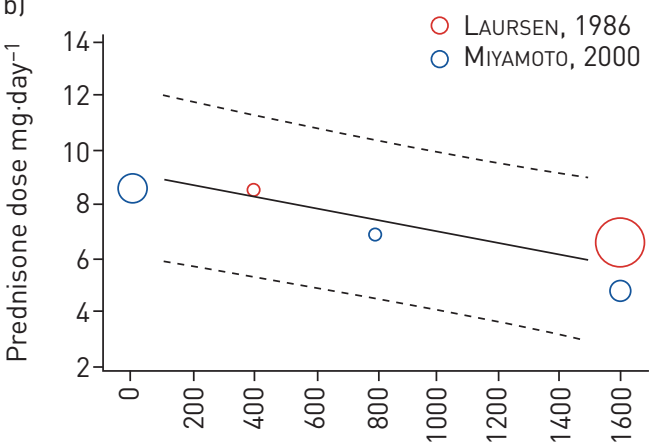

Budesonide dose $\mu \mathrm{g} \cdot \mathrm{day}^{-1}$

redicted mean prednisone dose $95 \% \mathrm{Cl}$ for mean prediction

FIGURE 3 Oral corticosteroid dose reduction in relation to inhaled corticosteroid dose. al Change from baseline of prednisone versus fluticasone dose; b) prednisone dose at study end-point versus budesonide dose; cl prednisone dose at study end-point versus beclomethasone dose.

day and $1200 \mu \mathrm{g}$ per day ICS dose, respectively. The meta-regression estimates were for a prednisone decrease of 2.14 (1.1-3.2) $\mathrm{mg}$ per $1000 \mu \mathrm{g}$ increase in budesonide. Figure $3 \mathrm{~b}$ shows the prednisone dose at study end-point versus budesonide dose.

Two studies (non placebo-controlled) had extractable data for BDP, with the highest dose $1500 \mu \mathrm{g}$ per day and $2000 \mu \mathrm{g}$ per day, respectively. The estimated prednisone difference $(95 \% \mathrm{CI})$ at end-point between the highest and lowest dose was $1.6(-1.8-5.0) \mathrm{mg}$ [14] and $4.3(-0.6-9.2) \mathrm{mg}$ [21]. The meta-regression estimates were for a prednisone decrease of $3.0(-10.4-16.4) \mathrm{mg}$ per $1000 \mu \mathrm{g}$ increase in BDP. Figure 3c shows the prednisone dose at study end-point versus BDP dose.

Two placebo-controlled studies had extractable data for mometasone, with the highest dose of $1600 \mu \mathrm{g}$ per day. The estimated prednisone difference $(95 \%$ CI) in change from baseline between the highest and lowest dose was $15.0(0-30) \mathrm{mg}$ [13] and 14.1 (3.5-26.7) $\mathrm{mg}$ [15]. As both studies did not provide data on level of covariance, these confidence intervals are based on pooled standard deviations.

\section{Primary inferential outcome}

For fluticasone propionate the proportion of the prednisone-sparing effect due to the systemic effects per $1000 \mu \mathrm{g}$ ICS was 1.02 (95\% CI 0.68-2.08). For budesonide the proportion of the prednisone-sparing effect due to the systemic effects per $1000 \mu \mathrm{g}$ was 0.93 (95\% CI 0.63-1.89) (table 3 and figure 4).

\section{Total elimination of oral corticosteroid}

Extractable data on total elimination of oral corticosteroid in relation to ICS dose was available in eight studies, shown in table 2 . The odds ratio $(95 \% \mathrm{CI})$ for oral corticosteroid elimination and ICS dose increase by $1000 \mu \mathrm{g}$ was budesonide 4.50 (2.44-8.30), $\mathrm{p}<0.001$; fluticasone 8.05 (4.99-12.99), $\mathrm{p}<0.001$; mometasone 3.01 (1.37-6.64), $\mathrm{p}=0.006$; and ciclesonide 2.48 (1.13-5.43), $\mathrm{p}=0.023$. For BDP no statistically significant association between was found: $1.88(0.25-14.2), \mathrm{p}=0.54$. 
TABLE 3 Proportion of oral corticosteroid (OCS)-sparing effect of inhaled corticosteroids (ICS) due to systemic absorption

\begin{tabular}{lccc} 
& $\begin{array}{c}\text { OCS dose reduction in } \\
\text { relation to } 1000 \mu \mathrm{g} \text { increase } \\
\text { in ICS dose }(95 \% \mathrm{CI})\end{array}$ & $\begin{array}{c}\text { OCS dose resulting in } \\
\text { same adrenal suppression } \\
\text { as } 1000 \mu \text { of ICS }\end{array}$ & $\begin{array}{c}\text { Ratio } \\
(95 \% \mathrm{CI})\end{array}$ \\
\hline $\begin{array}{l}\text { Fluticasone propionate } \\
\text { Budesonide }\end{array}$ & $4.9 \mathrm{mg}(2.4-7.4)$ & $5 \mathrm{mg}$ & $1.02(0.68-2.08)$ \\
\hline
\end{tabular}

\section{Discussion}

Key findings

This systemic review and meta-analysis of randomised controlled trials of the oral corticosteroid-sparing effect of ICS in oral steroid-dependent asthma has shown that high-dose ICS results in a dose-associated decrease in prednisone dose. The point estimates suggest that the majority of the oral corticosteroid dose-sparing effect can be attributed to their systemic absorption, rather than local airways effects. However, this finding should be interpreted with caution due to the small number of studies describing the dose equivalence for prednisone to ICS in terms of systemic effects and the imprecision of the doseresponse estimates with wide confidence intervals. With these limitations in mind, the lower confidence bounds of the estimates suggest that $\geqslant 60 \%$ of the oral corticosteroid dose reduction can be attributed to the effects from systemic absorption of high-dose ICS. The clinical relevance of this finding is that increasing the ICS dose to high or very high doses may require similar consideration as starting maintenance low-dose oral corticosteroids.

\section{Limitations of the study}

When interpreting the results of this meta-analysis, there are a number of methodological considerations. As in all systemic reviews, this review was restricted by the quality of existing research and the way in which data were reported. The number of papers that met our eligibility criteria was limited; consequently, the analyses per ICS type were performed by pooling a relatively small number of studies. Because of the limited number of studies investigating oral corticosteroid-sparing effects, we have pooled studies that used DPI with studies that used MDI. Several studies have demonstrated no significant difference in potency

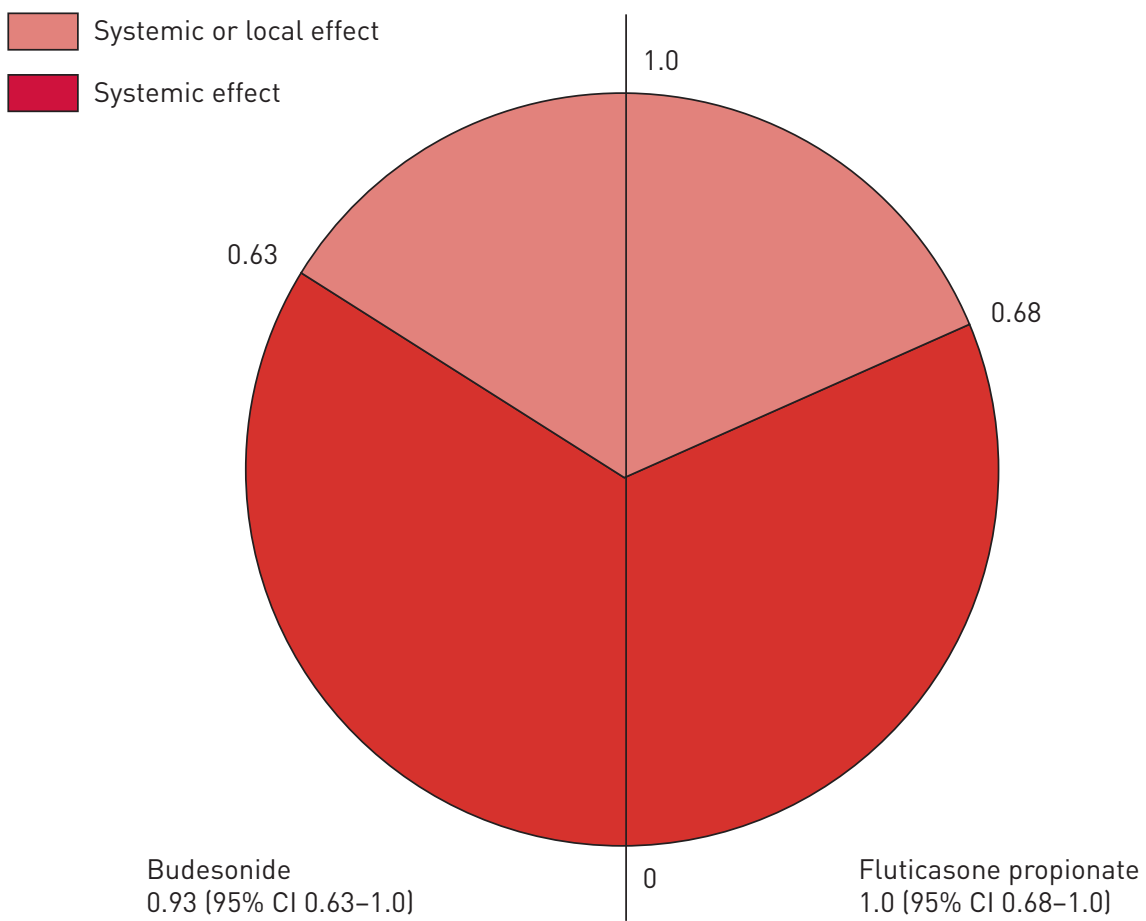

FIGURE 4 Proportion of oral corticosteroid-sparing effect of inhaled corticosteroid due to systemic absorption. 
between the two inhaler types [26]. Although most studies used prespecified protocols for reduction of prednisone, their methods differed across the studies. Furthermore, the standard deviation of prednisone dose reduction was wide in the majority of studies. In some studies, a large proportion of participants completely eliminated their prednisone use. Particularly for the studies that were pooled based on mean prednisone at the final outcome, the data may be highly skewed and normal distribution based methods may not be appropriate. Although the majority of the studies did not provide information on sequence generation or allocation concealment, all had a double-blind study design.

There is little published literature comparing the systemic effects of oral corticosteroid and ICS. We based our assessment on the measurement of adrenal suppression as it is a sensitive marker of adverse systemic ICS effects and provides the most appropriate surrogate marker for clinically relevant systemic effects of ICS [27]. We chose to only include studies utilising the ACTH-stimulation test, and excluded measures of adrenal function such as serial plasma and urinary cortisol level measurement. While these other methods may be sensitive for the detection of systemically bioavailable ICS, they are poor predictors of clinically significant effects, including adrenal suppression [28-32]. It should be noted that both AARONSON et al. [11] and Masoli et al. [10] evaluated the level of adrenal suppression using the high-dose ACTH test $(250 \mu \mathrm{g})$. While this test remains popular as a quick and safe method for diagnosing adrenal insufficiency, there are concerns regarding the diagnostic accuracy of using high-dose ACTH. In patients with secondary adrenal insufficiency, the supraphysiological dose of ACTH may mask adrenal insufficiency, resulting in false negatives [33-35]. The lower and more physiological 1- $\mu$ g ACTH test has been recommended by some as an alternative to the high-dose ACTH test. The low-dose test has proven to be more sensitive and more discriminating than the high-dose test in diagnosing adrenal insufficiency [34-38]. Conversely, some studies have shown that the results in diagnosing secondary adrenal failure using both high- and low-dose ACTH stimulation tests did not differ [39, 40]. Regardless, as this testing was undertaken in all randomised comparator groups, it will not bias the assessment of comparative effects between randomised treatments.

The dose equivalence of ICS to oral corticosteroid in terms of adrenal suppression by measurement of ACTH-stimulation tests could be estimated for budesonide and fluticasone propionate. The estimate for fluticasone propionate was based on a meta-analysis of three studies [24, 25, 41], whereas the estimate for budesonide was based on a single study [11], both resulting in wide confidence intervals. This has resulted in uncertainty regarding the precision of the estimates of equivalence between the systemic effects of ICS and oral corticosteroids, on which the primary outcome was derived. Furthermore, different patient populations were included in the studies relating to oral corticosteroid dose sparing and those studies relating to ICS and systemic effects. Therefore, relating the results of these studies to one another should be interpreted with caution, particularly in view of the report of a nonsignificant two-fold greater systemic potency between ICS relative to oral prednisone with non-oral steroid-dependent compared with oral steroid-dependent adult asthma [42]. We were not able to assess possible nonlinear effects in these datasets. However, several studies have shown a linear relationship between increasing ICS dose and the risk of adrenal suppression [10], fractures [5], cataracts [4] and diabetes [6].

\section{Implications of the findings}

This analysis confirms that the subset of patients with severe, oral corticosteroid-dependent asthma benefit from high or very high doses of ICS $[43,44]$. This is illustrated by the 2.5 - to eight-fold increase in the probability of oral corticosteroid elimination with ICS dose increase per $1000 \mu \mathrm{g}$ observed for budesonide, fluticasone, mometasone and ciclesonide. However, it is likely that the major component of the steroid-sparing effects of high doses of ICS in this severe subgroup is due to their systemic effects. These may relate to their inhibitory role in the recruitment and survival of inflammatory cells in the airways and are also involved in switching on genes that have anti-inflammatory effects [45].

The dose equivalence between oral corticosteroid and ICS for effects on adrenal function provides a useful guide for prescribers in clinical practice. Despite the uncertainty in the estimates, available data suggest that $1000 \mu \mathrm{g}$ fluticasone propionate has similar systemic effects as $5 \mathrm{mg}$ prednisone [10], and that $2500 \mu \mathrm{g}$ budesonide has similar systemic effects as $5 \mathrm{mg}$ prednisone [11]. It would be reasonable to suggest that prescribers should advise patients of this bioequivalence to enable the patient to put the risk into perspective.

The clinical relevance of these findings have been acknowledged in the most recent 2019 update of the GINA guidelines [46] in which ICS/LABA therapy with an ICS dose of $>500 \mu \mathrm{g}$ fluticasone propionate or equivalent is now recommended at step 5 , the same level as low-dose maintenance oral corticosteroid. This represents a change from the previous versions in which such high doses in combination ICS/LABA therapy were recommended at step 4 . While recognising the limited available data and the substantive limitations of the analyses undertaken in the review, we cautiously suggest that the clinical implication is 
that increasing the dose of ICS to high or very high doses requires similar considerations as starting maintenance low-dose oral corticosteroid therapy. Furthermore, it suggests that an alternative to increasing the dose of ICS to high or very high doses may be to start maintenance low-dose oral corticosteroid therapy.

Conflict of interest: I. Maijers has nothing to disclose. N. Kearns has nothing to disclose. J. Harper has nothing to disclose. M. Weatherall has nothing to disclose. R. Beasley reports grants from Health Research Council of New Zealand, during the conduct of the study; grants and personal fees for lectures and advisory board work, and travel expenses to attend meetings from AstraZeneca, grants from GlaxoSmithKline and Genentech, personal fees for advisory board work and travel expenses to attend meetings from Theravance Biopharma, outside the submitted work.

Support statement: The MRINZ is supported by Independent Research Organisation funding by the Health Research Council of New Zealand. Funding information for this article has been deposited with the Crossref Funder Registry.

\section{References}

1 Global Initiative for Asthma (GINA). Global Strategy for Asthma Management and Prevention. 2018. Available from: http://ginasthma.org

2 Holt S, Suder A, Weatherall M, et al. Dose-response relation of inhaled fluticasone propionate in adolescents and adults with asthma: meta-analysis. BMJ 2001; 323: 253-256.

3 Broersen LHA, Pereira AM, Jørgensen JOL, et al. Adrenal insufficiency in corticosteroids use: systematic review and meta-analysis. J Clin Endocrinol Metab 2015; 100: 2171-2180.

4 Weatherall M, Clay J, James $\mathrm{K}$, et al. Dose-response relationship of inhaled corticosteroids and cataracts: a systematic review and meta-analysis. Respirology 2009; 14: 983-990.

5 Weatherall M, James K, Clay J, et al. Dose-response relationship for risk of non-vertebral fracture with inhaled corticosteroids. Clin Exp Allergy 2008; 38: 1451-1458.

6 Suissa S, Kezouh A, Ernst P. Inhaled corticosteroids and the risks of diabetes onset and progression. Am J Med 2010; 123: 1001-1006.

$7 \quad$ Marks GB, Correll PK, Williamson M. Asthma in Australia 2005. Med J Aust 2005; 183: 445-446.

8 Covvey JR, Johnston BF, Wood F, et al. Changes to inhaled corticosteroid dose when initiating combination inhaler therapy in long-acting $\beta$ agonist-naive patients with asthma: a retrospective database analysis. Thorax 2014; 69: 1056-1058.

9 Pavord ID, Beasley R, Agusti A, et al. After asthma: redefining airways diseases. Lancet 2018; 391: 350-400.

10 Masoli M, Weatherall M, Holt S, et al. Inhaled fluticasone propionate and adrenal effects in adult asthma: systematic review and meta-analysis. Eur Respir J 2006; 28: 960-967.

11 Aaronson D, Kaiser H, Dockhorn R, et al. Effects of budesonide by means of the Turbuhaler on the hypothalmic-pituitary-adrenal axis in asthmatic subjects: a dose-response study. J Allergy Clin Immunol 1998; 101: 312-319.

12 Bateman E, Karpel J, Casale T, et al. Ciclesonide reduces the need for oral steroid use in adult patients with severe, persistent asthma. Chest 2006; 129: 1176-1187.

13 Fish JE, Karpel JP, Craig TJ, et al. Inhaled mometasone furoate reduces oral prednisone requirements while improving respiratory function and health-related quality of life in patients with severe persistent asthma. J Allergy Clin Immunol 2000; 106: 852-860.

14 Hummel S, Lehtonen L. Comparison of oral-steroid sparing by high-dose and low-dose inhaled steroid in maintenance treatment of severe asthma. Lancet 1992; 340: 1483-1487.

15 Karpel JP, Nayak A, Lumry W, et al. Inhaled mometasone furoate reduces oral prednisone usage and improves lung function in severe persistent asthma. Respir Med 2007; 101: 628-637.

16 Laursen LC, Taudorf E, Weeke B, et al. High-dose inhaled budesonide in treatment of severe steroid-dependent asthmatics. Eur J Respir Dis 1986; 68: 19-28.

17 Miyamoto T, Takahashi T, Nakajima S, et al. A double-blind, placebo-controlled steroid-sparing study with budesonide Turbuhaler in Japanese oral steroid-dependent asthma patients. Respirology 2000; 5: 231-240.

18 Nelson HS, Bernstein IL, Fink J, et al. Oral glucocorticosteroid-sparing effect of budesonide administered by Turbuhaler: a double-blind, placebo-controlled study in adults with moderate- to-severe chronic asthma. Chest 1998; 113: 1264-1271.

19 Nelson HS, Busse WW, DeBoisblanc BP, et al. Fluticasone propionate powder: oral corticosteroid-sparing effect and improved lung function and quality of life in patients with severe chronic asthma. J Allergy Clin Immunol 1999; 103: 267-275.

20 Noonan M, Chervinsky P, Busse WW, et al. Fluticasone propionate reduces oral prednisone use while it improves asthma control and quality of life. Am J Respir Crit Care Med 1995; 152: 1467-1473.

21 Tarlo SM, Broder I, Davies GM, et al. Six-month double-blind, controlled trial of high dose, concentrated beclomethasone dipropionate in the treatment of severe chronic asthma. Chest 1988; 93: 998-1002.

22 A randomized, double-blind, placebo-controlled comparative trial of fluticasone propionate $440 \mathrm{mcg}$ BID or $880 \mathrm{mcg}$ BID versus placebo administered via metered-dose inhaler in propellant 11/12 or GR106642X in adolescent and adult oral corticosteroid dependent asthmatics. www.gsk-studyregister.com/study/FLTA3022?legacy=true\&search=study. Date last updated: August 28, 2019.

23 Adams NP, Bestall JC, Jones P, et al. Fluticasone at different doses for chronic asthma in adults and children. Cochrane Database Syst Rev 2008; 4: CD003534.

24 Kellerman D, Stricker W HW. Effects of inhaled fluticasone propionate (FP) on the HPA axis of patients with asthma. Eur Respir J 1996; 9: Suppl. 23, 162s.

25 Sorkness CA, LaForce C, Storms W, et al. Effects of the inhaled corticosteroids fluticasone propionate, triamcinolone acetonide, and flunisolide and oral prednisone on the hypothalamic-pituitary-adrenal axis in adult patients with asthma. Clin Ther 1999; 21: 353-367.

26 Brocklebank D, Wright J, Cates C. Systematic review of clinical effectiveness of pressurised metered dose inhalers versus other hand held inhaler devices for delivering corticosteroids in asthma. BMJ 2001; 323: 896-900. 
27 Daley-Yates PT. Inhaled corticosteroids: potency, dose equivalence and therapeutic index. Br J Clin Pharmacol 2015; 80: 372-380.

28 Longui CA, Vottero A, Harris AG, et al. Plasma cortisol responses after intramuscular corticotropin 1-24 in healthy men. Metabolism 1998; 47: 1419-1422.

29 Jennings $\mathrm{BH}$, Andersson KE, Johansson SÅ. Assessment of systemic effects of inhaled glucocorticosteroids: comparison of the effects of inhaled budesonide and oral prednisolone on adrenal function and markers of bone turnover. Eur J Clin Pharmacol 1991; 40: 77-82.

30 Allen DB. Sense and sensitivity: assessing inhaled corticosteroid effects on the hypothalamic-pituitary-adrenal axis. Ann Allergy Asthma Immunol 2002; 89: 537-539.

31 Bernstein DI, Allen DB. Evaluation of tests of hypothalamic-pituitary-adrenal axis function used to measure effects of inhaled corticosteroids. Ann Allergy Asthma Immunol 2007; 98: 118-127.

32 Allen DB, Bielory L, Derendorf $\mathrm{H}$, et al. Inhaled corticosteroids: past lessons and future issues. J Allergy Clin Immunol 2003; 112: S1-S40.

33 Colao A, Pivonello R. The diagnosis of secondary adrenal insufficiency: low dose $v s$ high dose ACTH stimulation test. J Endocrinol Invest 2003; 26: 1-2.

34 Rasmuson S, Olsson T, Hagg E. A low dose ACTH test to assess the function of the hypothalamic-pituitary-adrenal axis. Clin Endocrinol 1996; 44: 151-156.

35 Thaler LM, Blevins LS. The low dose $(1-\mu \mathrm{g})$ adrenocorticotropin stimulation test in the evaluation of patients with suspected central adrenal insufficiency. J Clin Endocrinol Metab 1998; 83: 2726-2729.

36 Kazlauskaite R, Evans AT, Villabona C V, et al. Corticotropin tests for hypothalamic-pituitary- adrenal insufficiency: a metaanalysis. J Clin Endocrinol Metab 2008; 93: 4245-4253.

37 Nieman LK. Dynamic evaluation of adrenal hypofunction. J Endocrinol Invest 2003; 26: 7 Suppl., 74-82.

38 Dickstein G. The assessment of the hypothalamo-pituitary-adrenal axis in pituitary disease: are there short cuts? J Endocrinol Invest 2003; 26: 7 Suppl., 25-30.

39 Grebe SKG, Feek CM, Durham JA, et al. Inhaled beclomethasone dipropionate suppresses the hypothalamopituitary-adrenal axis in a dose dependent manner. Clin Endocrinol 1997; 47: 297-304.

40 Suliman AM, Smith TP, Labib M, et al. The low-dose ACTH test does not provide a useful assessment of the hypothalamic-pituitary-adrenal axis in secondary adrenal insufficiency. Clin Endocrinol 2002; 56: 533-539.

$41 \mathrm{Li} \mathrm{JT}$, Goldstein MF, Gross GN, et al. Effects of fluticasone propionate, triamcinolone acetonide, prednisone, and placebo on the hypothalamic-pituitary-adrenal axis. J Allergy Clin Immunol 1999; 103: 622-629.

42 Toogood JH, Baskerville J, Jennings B, et al. Bioequivalent doses of budesonide and prednisone in moderate and severe asthma. J Allergy Clin Immunol 1989; 84: 688-700.

43 Adams N, Bestall J, Jones P. Inhaled fluticasone at different doses for chronic asthma. Cochrane Database Syst Rev 2002; 1: CD003534.

44 Chung KF, Wenzel SE, Brozek JL, et al. International ERS/ATS guidelines on definition, evaluation and treatment of severe asthma. Eur Respir J 2014; 43: 343-373.

45 Barnes PJ. Molecular mechanisms and cellular effects of glucocorticosteroids. Immunol Allergy Clin North Am 2005; 25: 451-468.

46 Global Initiative for Asthma (GINA). Pocket Guide for Asthma Management and Prevention. 2019. https:// ginasthma.org/wp-content/uploads/2019/04/GINA-2019-main-Pocket-Guide-wms.pdf 